be made. Transference to fresh plants and subsequent growth does not add a satisfactory control to our experiments, since it is impossible in this way to avoid transferring many times the number of bacilli which are planted from a thin emulsion by means of the very fine, hair-like, capillary employed originally. Nothing resembling cven the beginnings of an extracellular colony has been noticed by us. It is, moreover, not as a method of cultivation that our technic is of chief interest, but rather as admitting of the direct study of bacteria in their reaction with living tissue cells.

It is an interesting fact that in many unsuccessful plants the rat lepra bacilli, usually so resistant, have almost completely disappeared within a week or ten days. As this is in distinct contrast to a number of experiments carried out by Dr. M. C. Terry, in which the rat lepra bacilli were kept for periods of weeks in mediums containing large numbers of leukocytes, both polynuclear and mononuclear, without disintegration or growth, it would seem to indicate that the tissue cells may exert a destructive influence on these bacteria not possessed by the usual phagocytic cells.

While it is not the purpose of this paper to discuss at length the histologic features of rat leprosy, it is of interest in this connection to note that in preparations from Iymph-nodes of infected rats we have often observed the bacilli almost exclusively intracellular. This corresponds to the observations, in human lepra, of Hansen and Neisser and the more recent ones of Gurd. It would appear, therefore, that, as in human lepra, in the disease of the rat the growth of the bacilli takes place within the tissue cells rather than in the intercellular spaces.

The technic developed during these experiments has encouraged us to believe that we possess, in the plasmatissue preparations, an instrument of great value in studying directly certain phases of the reactions between tissue cells and bacteria not amenable to direct experimental approach in the past.

Dust in the Cotton Industry.-Dust is a prolific source of inefficiency and of morbidity in many industries. Among them is the cotton industry, in some phases of which the problem of dust is a serious menace to the health of the employees, and more recently vigorous and intelligent efforts have been put forth to overcome this difficulty. In the cotton factories, the carding-machines seem to be the source of the greatest amount of dust and employees in this branch are seldom able to follow their employment to a normal age. It is in stripping the carding-machines that the most dust is produced and employees have adopted the expedient of holding a bunch of cotton between their lips to avoid inhaling the cotton fibers. Various respirators have also, been used Which cover the nose and mouth; but in modern factories various devices have been used to impound the dust from the machines as it is made, mostly consisting of hoods fitting over the dust-making cylinders, the offending material being carried of by air currents. A number of such devices are pictured in the Scientifio American, Dec. 30; 1911, and are described by J. I. Crabtree. The operation of stripping or cleaning the carding-machines needs only be performed a few times a day and requires only a few minutes for ench Inachine. The apparatus is so arranged that the full force of the exliaust fan or blower mny be concentrated on one machine, which gathers up all the dust as it is being cleaned. The exhaust apparatus may be used in the intervals for withdrawing bad air from the work-room generally. It is found that these improved forms of dist extractors work admirably and that the health and efficiency of the cmployees are improved, and also that the removal of the dust improves the quality of the finished yarn.

\section{THE TREATMENT OF OCCLUDED "S"}

E. W. SCRIPTURE, Pir.D., M.D.

Assoclate in I'sychlatry in Columbla Unlversity NEW YORK

One of the most frequent defects in speech found among the illiterate or the defective is the occluded "s."

In making the normal " $\mathrm{s}$ " the tongue is pressed against the hard palate rather tightly, but a narrow groove is left in the middle so that a jet of air passes through. The method of palatography - a very thin black artificial palate covered with chalk is held in the mouth while the sound is being produced-gives a record like that in Figure 1A; the black surfaces indicate where the tongue presses against the hard palate. It is the jet of air through the narrow channel that produces the distinctive sound of "s."

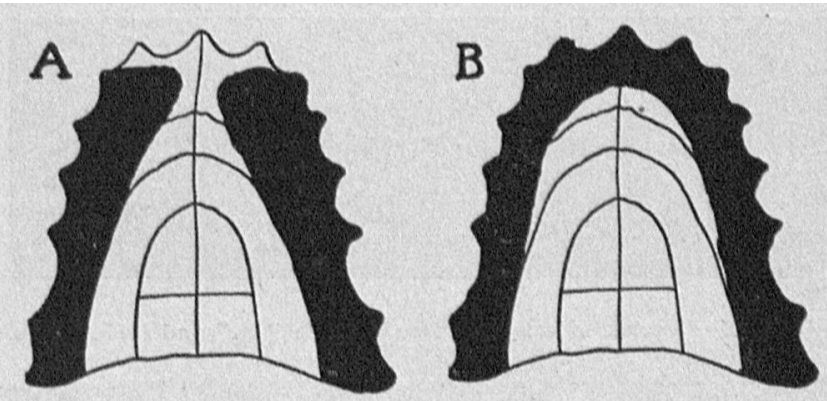

Fig. 1.-A, normal contact of the tongue with the painte in maliIng "B." B, tongre contuct tor occluded "s."

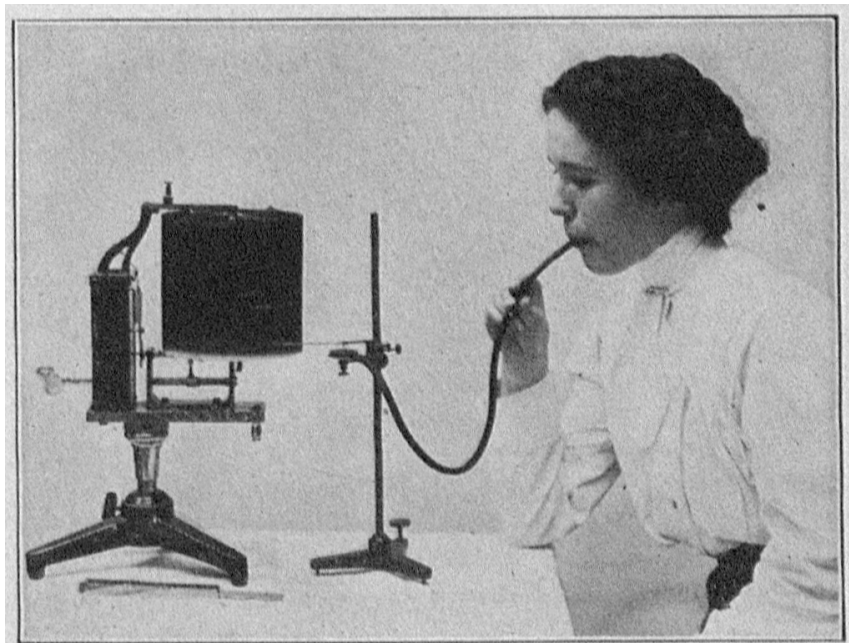

Fig. 2.-Apparntus for mnking records of tongue-pressure. A smail rubber bult is hold behind the tecth nbove the tongue. A tube from it transmits the movements by alr-pressure to the recording apparatus; this draws a white line on the moving surface.

A child with the occluded " $\mathrm{g}$ " apparently uses " $\mathrm{t}$ " and "d" instead of " $s$ " and "z," saying "tun," "toap," "toup," instead of "sun," "soap," "soup"; or "dode," "Liddy," instead of "doze," "Lizzv."

A palatogram for the occluded " $\mathrm{s}$ " is given in Figure 113. The black surface shows that the tongue stretches across the front of the palate and thus closes the narrow channel.

If a small rubber bulb placed between the front of the tongue and the palate is connected to a manometer or a registering apparatus (Fig. 2), the force of the pressure can be indicated. For an occluded " $\mathrm{s}$ " it is greater than for the ordinary "s" or for "t" (Fig. 3).

The occluded " $\mathrm{s}$ " is thus not the same as the "t"; it may be defined as an " $\mathrm{s}$ " made with excessive tonguepressure resulting in a sound like "t." 
Trentment by having the child imitate the "s" of a normal person usually agraravates the defect; he is already making too much effort with his tongue and the more he tries the greater the effort he makes. Sometimes he can be taught directly to relax the tongue, but this rarely succeeds.

It is sometimes effective to tell the child to stick his tongue between the teeth whenever he wants to say "s"; this has the disalvantage of replacing an incorrect sound by another incorrect sound, although the new sound is nearer the correct one.

The treatment that 1 have introduced is to place a small stick probe over the middle of the tongue while the patient is saying " $\mathrm{s}$ " (Fig. 4). 'J'his produces a groove through which the air escapes with a hissing sound, and the child cannot possibly make a sound that is like a "t." Even a normal person is forced to say

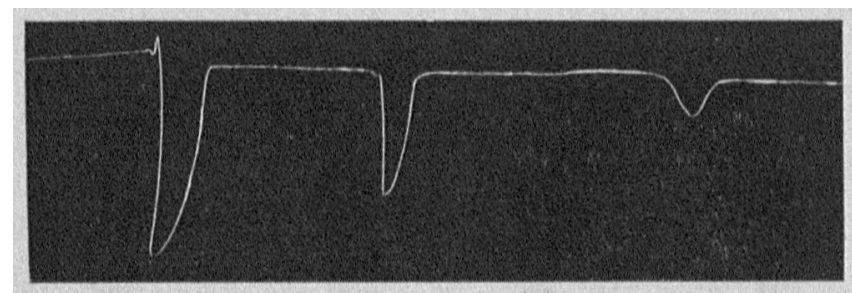

Fig. 3.-Records of tongue-pressure for "s," "t" and occluded "s."

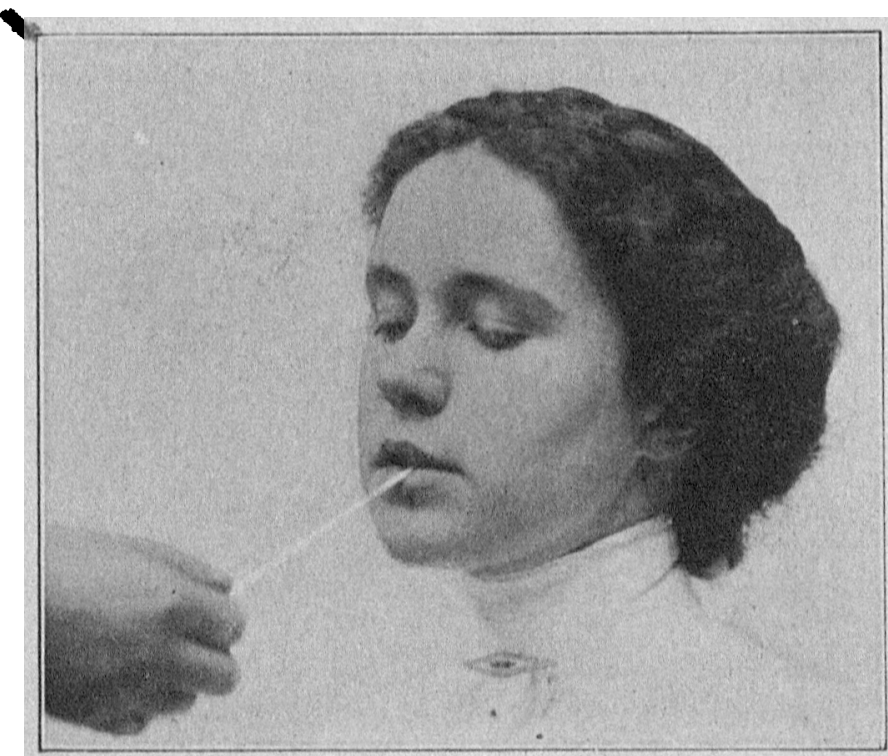

Wig. 4.-Correcting occluded "в."

"sop," "sick," "sap" when he tries to say "top," "tick," "tap." With repeated trials the new sound catches the patient's ear and he learns to replace his occluded "s" by this sound without the aid of the stick.

130 West Seventieth Street.

The Nervous Patient.-lt is ocensionally the practice of physicians to try to persuade nervous patients that there is really notling the mutter with them. Such a course is the gravest folly, for it liss but the effect of discouraging the patient (since he is certuin that thers is something the mat. ter with him), and decreasing his contidence in his physician. He feels sick, and no amount of urging can persuade him to the contrary. Functional nervous disorders are just as definite as if they were orgnnic. The sooner the practitioner recognizes that something definite is the matter, and finds out what it is, the quicker he may effect a cure.-W. L. Cowles in the New England Med. Month.

\section{TIIE RESULTS OF TIIE TIREATMENT OF} CANCFR OF THE UTERUS BY THE ACTUAL CAUTERY, WITH A PRAC'IICAl, METHOD FOR I'T APPLICA'IION *

JAMES F. PERCY, M.D.

(iAt.ELHURG, ILL.

Any treatinent of cancer of the uterus, whether by the knife or the cautery, ean of necessity awaken but little enthusiasm. Until the embryologist, the pathologist and the bacteriologist widen our horizon as to the causes back of this condition, we can, by an honest exchange of experiences, hope only to prolong life, and with this add comfort to the unknown number of days that a given patient will live. No true idea of what any of our present-lay methods will aceomplish in the way of prolonging life in comfort, or of cure, can be known unless each surgeon who treats them at all reports his experiences in every instance, and never, under any circumstances, omits his final results in any case. The average primary mortnlity after the use of the knife in encer of the cervix and uterus is probably no less than it was when abdominnl and vaginal lysterectomy was first attempted. This, as we all know, is so lighh that it robs the subject, 1 repeat, of the zeal that we night otherwise lave for it.

But cancer of the uterus is a real fact in our daily work. The ordinary fellow of our number sees relatively as many as the master-surgeon. The latter can do a Ries-Wertheim, the former cannot. I am sure that as far as womankind in general is concerned, it is most unfortunate that there nre not a few surgeons who do no other work than liysterectomies. Assuming that the liies-Wertheim operation is the lighest expression of skill and judgment for an abdominal lyysterectomy in eancer; it is to be regretted that all the eases developing in this country could not be turned over to the surgeon. who would attempt no other form of operative work. But we must all agree that this. desirable as it must be from the standpoint of the afticted, is but a surgical dream. If the knife, after all, is to remain for years yet to come, the important arbiter of the fate of the woman afficted with this disense, then the pullic, I am sure, will at no distant day demand that only the man thus trained be griven this work.

But, personally, I belicve that the removal of the cancerous uterus by the knife is nothing less than legalized assassination. Say what we will, the primary operative mortality is absolutely unknown. It is unknown simply because it is so oppressively high; and when this is true in any operative condition, the rule is that only the exceptional recoveries and the apparent cures creep into the literature. In view, therefore, of the ligh primary mortality, as well as its moral and sociologic aspects, I will dismiss, for the purposes of this paper, the sulbject of hysterectomy from an operative standpoint, total, complete, or otherwise, as not worth the effort.

In its place, I want to offer a procedure which is based on the work of the experimental laboratory, and, in addition, an improved method of its application. As far as I can learn, the basis of the procedure is new in the details of its use, and this is also true of the method by which I limit the destructive effects of the enutery

- Rend breoro the Western Surgleal Association, Kansus City. Mo., December, 1011 . 